TP Periodica Polytechnica Mechanical Engineering

62(3), pp. 209-217, 2018

https://doi.org/10.3311/PPme.11972

Creative Commons Attribution (i)

RESEARCH ARTICLE

\section{Aerodynamics and Heat Transfer over Solid-Deflectors in Transverse, Staggered, Corrugated-Upstream and Corrugated-Downstream Patterns}

\author{
Younes Menni ${ }^{1 *}$, Ahmed Azzi ${ }^{1,2}$, Ali J. Chamkha ${ }^{3,4}$ \\ Received 17 January 2018; accepted after revision 03 May 2018
}

\begin{abstract}
Computational fluid dynamic simulations were conducted to analysis the influences of two different deflector orientations on turbulent forced-convection flow and skin friction loss of two-dimensional horizontal rectangular cross section channels with upper and lower wall-attached corrugated baffles. The governing flow equations, i.e., continuity, momentum, and energy, were numerically solved by the Finite Volume Method (FVM) using the Semi-Implicit Method for Pressure Linked Equation (SIMPLE) discretization formulation. The help of the CFD code FLUENT was employed to solve the dynamic and thermal behavior of air in the whole domain under investigation. The flow rate in terms of Reynolds number is ranged from 5,000 to 32,000. The obtained results show that augmenting the Reynolds number makes the dynamic thermo energy field redirect in the vicinity of deflector corners, and forces an augmentation in the thermal transfer rate from baffles.
\end{abstract}

\section{Keywords}

corrugated deflector, thermal transfer, turbulent air flow, numerical simulation

\footnotetext{
${ }^{1}$ Unit of Research on Materials and Renewable Energies URMER, Department of Physics, Faculty of Sciences, Abou Bekr Belkaid University, BP 119-13000-Tlemcen, Algeria

${ }^{2}$ Mechanical Engineering Department, Faculty of Technology, Abou Bekr Belkaid University, BP 230-13000-Tlemcen, Algeria

${ }^{3}$ Mechanical Engineering Department, Prince Sultan Endowment for Energy and Environment, Prince Mohammad Bin Fahd University,

Al-Khobar 31952, Saudi Arabia
}

${ }^{4}$ RAK Research and Innovation Center, American University of Ras Al Khaimah, United Arab Emirates

" Corresponding author, e-mail: menniyounes.cfd@gmail.com

\section{Introduction}

Several researcher works have examined the baffled air channels numerically and experimentally to enhance the performance. Mokhtari et al. [1] numerically characterized and studied the mixed convection of a three-dimensional square duct with various arrangements of fins in both laminar and turbulent flow. This study focuses on the ability of fin arrangements to enhance a heat transfer while flow is incompressible and the fluid is air. The numerical results are validated with experimental data and show good agreement. The results presented in this study showed that efficient fin arrangement highly influences on the cooling performance of the plate. Promvonge et al. [2] carried out a numerical investigation to examine laminar flow and heat transfer characteristics in a three-dimensional isothermal wall square channel with $45^{\circ}$ angled baffles. Effects of different baffle heights on heat transfer and pressure loss in the channel were studied and the results of the $45^{\circ}$ inline baffle are also compared with those of the $90^{\circ}$ transverse baffle and the $45^{\circ}$ staggered baffle. The optimum thermal enhancement factor was at the $45^{\circ}$ baffle height of 0.2 times of the channel height for both arrays. The maximum thermal enhancement factor of the $45^{\circ}$ baffle in the Reynolds number range studied was found to be about 2.6 or twice higher than that of the $90^{\circ}$ transverse baffle. Yongsiri et al. [3] reported the results of numerical study of turbulent flow and heat transfer in a channel with inclined detached-ribs. In that study, the fluid flow, temperature field and thermal performance of the inclined detached-ribs with different attack angles (from $0^{\circ}$ to $165^{\circ}$ ), were examined and compared with those of the typical transverse attached rib with the attack value of $90^{\circ}$. The computational results showed that, at high Reynolds number, the inclined ribs with attack angles of $60^{\circ}$ and $120^{\circ}$ yield comparable heat transfer rates and thermal performance factors which were higher than those given by the ones with other angles. On the other hand, at low Reynolds number, the effect of rib attack angle was insignificant. Mellal et al. [4] numerically analyzed the thermal and dynamic characteristics in the shell side of a shell and tube heat exchanger (STHE) fitted with segmental baffles and different 
arrangements. Two primordial parameters were tested: baffles spacing of 106.6, 80 and $64 \mathrm{~mm}$ and six baffles inclination angles of $45,60,90,120,150$ and $180^{\circ}$. The numerical results showed the important role of the studied parameters in the shell side thermal performance enhancement, where the case of baffle inclination angle of $180^{\circ}$, at $64 \mathrm{~mm}$ of baffle spacing was the best design that assures mixing flow, giving thus a highest value of thermal performance factor of 3.55 compared with STHE without baffles. To provide an overview of the current state of the art of heat transfer augmentation schemes employed for internal cooling of turbine blades and components, results from an extensive literature review were presented by Ligrani [5] with data from internal cooling channels, both with and without rotation. The overall paper was presented in three major parts. Presented first is a brief review of developments up to 2003, considering investigations which do not include the effects of rotation. An overview of more recent developments since 2003 (without rotation issues considered) is presented next. The third and final part of the paper then addresses the effects of rotation on heat transfer augmentation technologies for internal cooling. Kumar and Kim [6] presented the heat transfer and fluid flow characteristics in a rib-roughened solar air heater channel. The artificial roughness of the rectangular channel was in the form of a thin circular wire in discrete multi V-pattern rib geometries. The effect of this geometry on heat transfer, fluid flow, and performance augmentation was investigated using the CFD (computational fluid dynamics). The roughness parameters were a relative discrete distance of 0.69 , a relative rib height of 0.043 , a relative rib pitch of 10 , a relative rib width of 6.0, and a flow-attack-angle of $60^{\circ}$. The discrete width ratios and Reynolds numbers ranged from 0.5 to 2.0 and from 2000 to 20,000, respectively. The thermo-hydraulic performance was found to be the best for the discrete width ratio of 1.0. A discrete multi V-pattern rib combined with dimple staggered ribs also had better overall thermal performance compared to other rib shapes. Kumar and Kim [7] reported heat transfer and fluid flow characteristics in a solar air heater channel with multi V-type perforated baffles. The flow passage has an aspect ratio of 10 . The relative baffle height, relative pitch, relative baffle hole position, flow attack angle, and baffle open area ratio are 0.6, 8.0, 0.42, $60^{\circ}$, and $12 \%$, respectively. The Reynolds numbers considered in the study was in the range of 3,000 - 10,000. The re-normalization group (RNG) k-epsilon turbulence model was used for numerical analysis, and the optimum relative baffle width was investigated considering relative baffle widths of $1.0-7.0$.The numerical results were in good agreement with the experimental data for the range considered in the study. Kumar et al. [8] experimentally investigated heat transfer and fluid flow characteristics in an air passage with different type of blockage arrangements as roughness elements employed over one wall. The different blockage arrangements such as transverse perforated blockage, angled perforated blockage, V-type solid blockage, V-type blockage with gap and V-type perforated blockage have been careful in this study. During the experimental examination air was passed through the test passage under a uniform wall heat flux of the heated wall plate. During the experimental study author found that the V-type perforated blockage provides better thermal hydraulic performance as compared with other type blockage air passage. Demartini et al. [9] investigated air flow through a rectangular channel with two plate baffles. Hot wire anemometry and the Finite Volume Method, by means of Commercial program Fluent 5.2 were applied, and a comprehensive analysis of the velocity profiles and pressure gradients was carried out in that work. Other authors studied in detail the effect of the size of baffles and orientations on the heat transfer enhancement in the tubes heat exchangers. Nasiruddin and Kamran Siddiqui [10] examined numerically three different orientations of baffles; the first case is a vertical baffle, the second inclined towards the downstream side, and the third inclined towards the upstream side. Menni and Azzi [11] carried out a computational fluid dynamic analysis of thermal and aerodynamic fields for an incompressible steady-state flow of a Newtonian fluid through a two-dimensional horizontal rectangular section channel with upper and lower wall-attached, vertical, staggered, transverse, cascaded rectangular-triangular (CRT), solid-type baffles, using the Commercial, Computational Fluid Dynamics, software Fluent. The impact of the cascaded rectangular-triangular geometry of the baffle on the thermal and dynamic behavior of air was shown and this in comparing the data of this obstacle type with those of the simple flat rectangular-shaped baffle. This CFD analysis can be a real application in the field of heat exchangers, solar air collectors, and electronic equipments. Amraoui and Aliane [12] presented the study of fluid flow and heat transfer in solar flat plate collector by using Computational Fluid Dynamics (CFD) which reduces time and cost. 3D model of the collector involving air inlet, the collector was modeled by ANSYS Workbench and the grid was created in ANSYS ICEM. The results were obtained by using ANSYS FLUENT and ANSYS CFX. The outlet temperature of air was compared with experimental results and there was a good agreement in between them. Other works can be found in the literature, i.e, Fodor [13], Rábai and Vad [14], Hegedus et al. [15], Füle and Hernádi [16], Goda and Bánhidi [17], Bidar et al. [18], Khrabry et al. [19], and Fenyvesi and Horváth [20].

The purpose of the current study is to investigate the turbulent forced-convection flow of air inside a two-dimensional horizontal rectangular cross section channel, containing two upper and lower wall-attached corrugated solid-type baffles as presented numerically and experimentally in more detail in Demartini et al. [9]. Two differently shaped baffles, i.e., corrugated-upstream and corrugated-downstream shaped, with the same cross-sectional areas were compared in a staggered 
manner. The effects of corrugated shape geometries of baffles as well as flow rates are investigated and analyzed numerically using the CFD Fluent software. In particular, plots contours of stream function, profiles of axial velocity, friction loss, heat transfer and thermal enhancement factor are obtained.

\section{Mathematical formulation}

\subsection{Geometry of the present problem}

The physical geometry considered in this study is shown in Fig. 1a, b and c. The system consists of airflow moving through a two-dimensional horizontal rectangular cross section channel provided with two upper and lower wall-mounted staggered corrugated transverse baffles (see Fig. 1a). Two different models of corrugated baffles were considered in this study, which are referred as cases A and B. In case A, a baffle corrugated towards the upstream end was considered (see Fig. 1b) and in case B, a baffle corrugated towards the downstream end was considered (see Fig. 1c).

\subsection{Governing equations}

The numerical model for fluid flow and heat transfer in the channel was developed under the following assumptions: (i) steady two-dimensional fluid flow and heat transfer, (ii) the flow is turbulent and incompressible, (iii) constant fluid properties, (iv) the body forces and viscous dissipation are ignored, and (v) the standard $k$-epsilon $(\varepsilon)$ turbulence model of Launder and Spalding [21] is used to simulate the fluid flow and heat transfer.

The governing flow equations, i.e., continuity, momentum and energy equations, used to simulate the incompressible steady fluid flow and heat transfer characteristics in the given computational domain are given as

$$
\begin{gathered}
\frac{\partial}{\partial x_{i}}=\left(\rho u_{i}\right)=0 \\
\frac{\partial}{\partial x_{i}}\left(\rho u_{i} u_{j}\right)=\frac{\partial}{\rho x_{i}}\left[\mu\left(\frac{\partial u_{i}}{\partial x_{j}}-\rho \overline{u_{i}^{\prime} u_{j}^{\prime}}\right)\right]-\frac{\partial P}{\partial x_{i}}
\end{gathered}
$$

where $\boldsymbol{\rho}$ is the fluid density, $P$ the pressure, $\boldsymbol{\mu}$ dynamic viscosity, $u_{i}$ and $u_{j}$ are mean velocity components in $x_{i}$ and $x_{j}$ directions.

$$
\frac{\partial}{\partial x_{i}}\left(\rho u_{i} T\right)=\frac{\partial}{\rho x_{i}}\left(\left(\Gamma+\Gamma_{t}\right) \frac{\partial T}{\partial x_{j}}\right)
$$

where $\boldsymbol{\Gamma}$ and $\Gamma_{t}$ are molecular thermal diffusivity and turbulent tharmal diffusivity, repectively and are given by

$$
\Gamma=\mu / \operatorname{Pr} \text { and } \Gamma_{t}=\mu_{t} / \operatorname{Pr}_{t}
$$

In Eq. (2), $\rho \overline{u_{i}^{\prime} u_{j}^{\prime}}$ is the Reynolds stresses defined by the Boussinesq hypothesis as

$$
-\rho \overline{u_{i}^{\prime} u_{j}^{\prime}}=\mu_{t}\left(\frac{\partial u_{i}}{\partial x_{j}}+\frac{\partial u_{j}}{\partial x_{i}}\right)-\frac{2}{3}\left(\rho k+\mu_{t} \frac{\partial u_{i}}{\partial x_{j}}\right) \delta_{i j}
$$

where $\delta_{i j}$ is the Kroenecker delta and $\boldsymbol{\mu}_{t}$ the eddy viscosity defined as

$$
\mu_{t}=\rho C_{\mu} \frac{k^{2}}{\varepsilon}
$$

The flow Reynolds number $(R e)$ based on channel aeraulic diameter

$$
D_{h}=2 H W /(H+W)
$$

is given by

$$
\operatorname{Re}=\rho \bar{U} D_{h} / \mu
$$

The skin friction coefficient $\left(C_{f}\right)$ is given by

$$
C_{f}=2 \tau_{w} / \rho \bar{U}^{2}
$$

The friction factor (f) is evaluated from the pressure drop $(\Delta \mathrm{P})$ as

$$
f=2(\Delta P / L) D_{h} / \rho \bar{U}^{2}
$$

where presents the average axial velocity of the section, and $\tau_{\mathrm{w}}$ is the shear stress to the wall.

For determining the heat transfer rate inside the channel, the heat transfer is measured by the local Nusselt number $\left(N u_{x}\right)$ which can be written as

$$
N u_{x}=h_{x} D_{h} / k_{f}
$$

and the average Nusselt number $(\mathrm{Nu})$ can be obtained by

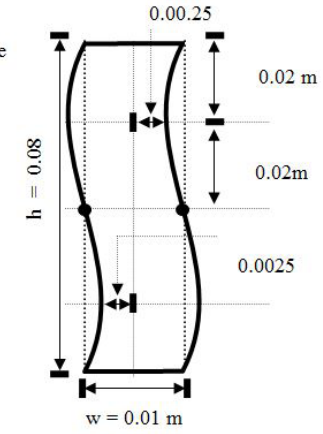

(b)

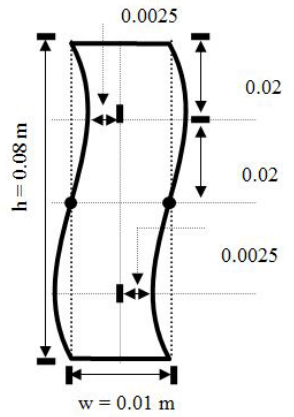

(c)

Fig. 1 a) The geometry of the system under investigation, b) Corrugated-upstream baffle: case A, c) Corrugated-downstream baffle: case B. 


$$
N u=\frac{1}{L} \int N u_{x} \partial x
$$

The following expression represents the thermal enhancement factor $(T E F)$ :

$$
T E F=\left(N u / N u_{0}\right) /\left(f / f_{0}\right)^{1 / 3}
$$

The quantities $N u_{0}$ and $f_{0}$ are the average Nusselt number and the friction factor of the smooth channel, respectively.

The Dittus and Boelter correlation has the form [22]:

$$
N u_{0}=0.023 \operatorname{Re}^{0.8} \operatorname{Pr}^{0.4} \text { for } \operatorname{Re} \geq 10^{4}
$$

The Petukhov correlation has the form [23]:

$$
f_{0}=(0.79 \ln \mathrm{Re}-1.64)^{-2} \text { for } 3 \times 10^{3} \leq \mathrm{Re} \leq 5 \times 10^{6}
$$

In this study, CFD modelling is performed using the commercial CFD software FLUENT.

\subsection{Boundary conditions}

The aerodynamic boundary conditions are set according to the numerical and experimental analysis of Demartini et al. [9] while the thermal boundary conditions are chosen according to the numerical investigation of Nasiruddin and Kamran Siddiqui [10]. A uniform one-dimensional profile of fluid velocity $(u=$ $\left.U_{i n}, v=0\right)$ at $27^{\circ} \mathrm{C}\left(T_{i n}=300 \mathrm{~K}\right)$ is introduced as the aeraulic boundary condition at the start of the whole domain investigated while an atmospheric pressure $(P=P a t m)$ outlet condition is applied at the channel outlet, as shown in Fig. 1. The inlet turbulence intensity was kept at $I=2 \%$. Impermeable boundary and no-slip wall conditions were implemented over the surfaces of the channel as well as the corrugated-baffle surface. A constant temperature of $102^{\circ} \mathrm{C}\left(T_{w}=375 \mathrm{k}\right)$ was applied on the top and bottom surfaces of the channel as the thermal boundary condition.

\section{Numerical solution}

A non-uniform grid system with a large concentration of nodes in regions of steep gradients, such as those close to the walls and corrugated baffles was employed, see Fig. 2. The grid independence tests were performed by realizing CFD simulations in the whole domain investigated, using different structured quadrilateral-type grid systems with the number of mesh nodes ranging from 35 to 145 along the pipe depth and 95 to 370 along the length $(95 \times 35 ; 120 \times 45 ; 145 \times 55 ; 170$ $\times 65 ; 195 \times 75 ; 220 \times 85 ; 245 \times 95 ;$ and $370 \times 145)$, for $R e=$ $8.73 \times 10^{4}$. The grid system with the number of nodes equal to $245 \times 95$ (in $X$ and $Y$ directions respectively) performs around $0.300 \%$, and $0.353 \%$ deviation for the $N u$, and $f$, respectively, in compared with the grid of size $370 \times 145$. Therefore, the grid cell of $245 \times 95$ is selected for the rest of our study.

The governing flow equations obtained with the associated boundary conditions is numerically solved by the Finite Volume Method (FVM) developed by Patankar [24] and the velocity-pressure coupling is treated using the SIMPLEalgorithm, details of which can be found in Patankar [24]. Terms corresponding diffusion equations of momentum and turbulence are discretized using the QUICK scheme in the form given by Leonard and Mokhtari [25] and a Second Order was used for the pressure terms [24]. For closure of the equations, the standard $k$-epsilon model of Launder and Spalding [21] was used in the present study. The criterions of convergence are set as: relative residual of $10^{-6}$ for the flow and $10^{-9}$ for the energy equation.

To attain the accurate aerodynamic prediction in the channel, the predictive ability of four different turbulence models, including, the standard $k-\varepsilon$ turbulence model, the Renormalized Group (RNG) $k-\varepsilon$ turbulence model, the standard $k-\omega$ turbulence model, and the Shear Stress Transport (SST) $k$ - $\omega$ turbulence model, were investigated by Eiamsa-ard and Promvonge [26]. The predicted results from using several turbulence models reveal that the RNG and the $k-\varepsilon$ turbulence models generally provide better agreement with available measurements than others. Therefore, the $k-\varepsilon$ model is selected to use in prediction of this complex flow.

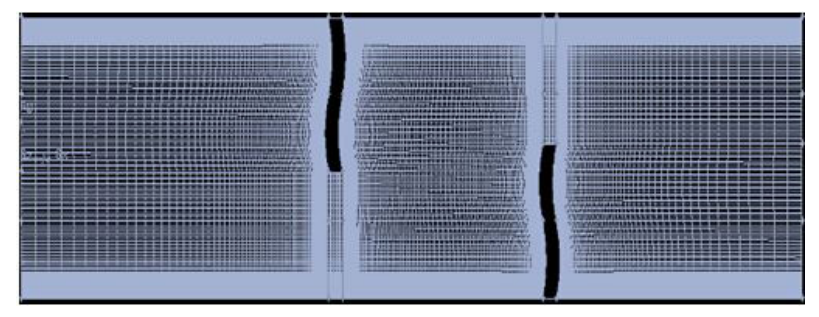

(a)

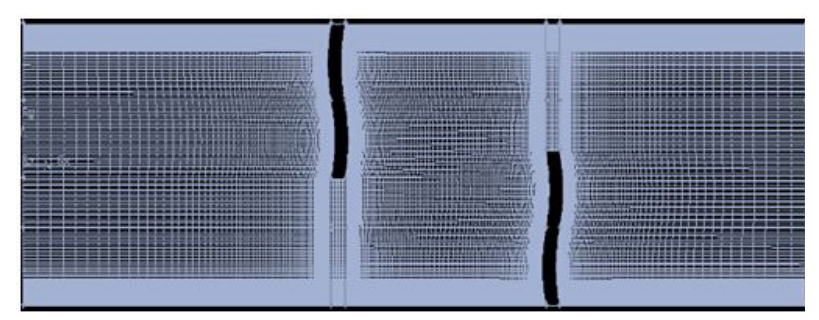

(b)

Fig. 2 Mesh generated on the computational domain for both the corrugated baffle cases under study: a) Corrugated-upstream baffles: case A, b) Corrugated-downstream baffles: case B.

To validate the precision of the numerical model, the axial velocity profile distribution profile obtained from the current study was compared with the one obtained from the numerical and experimental analysis of Demartini et al. [9] for the turbulent flow of air inside a horizontal rectangular channel, where two baffle plates were placed in opposite walls.

Fig. 3 shows the quantitative comparison between both numerical and experimental profiles of axial velocity after the lower wall baffle, near the channel outlet at the position given by $x=0.554 \mathrm{~m}, 0.029 \mathrm{~m}$ before the exit. Both the experimental and numerical velocity profiles are computed for a Reynolds number equal to $R e=8.73 \times 10^{4}$. As seen in this figure, there is a good 
agreement between both the numerical and experimental velocity profiles, indicating that the present numerical simulation can accurately predict fluid flow and pressure loss characteristics.

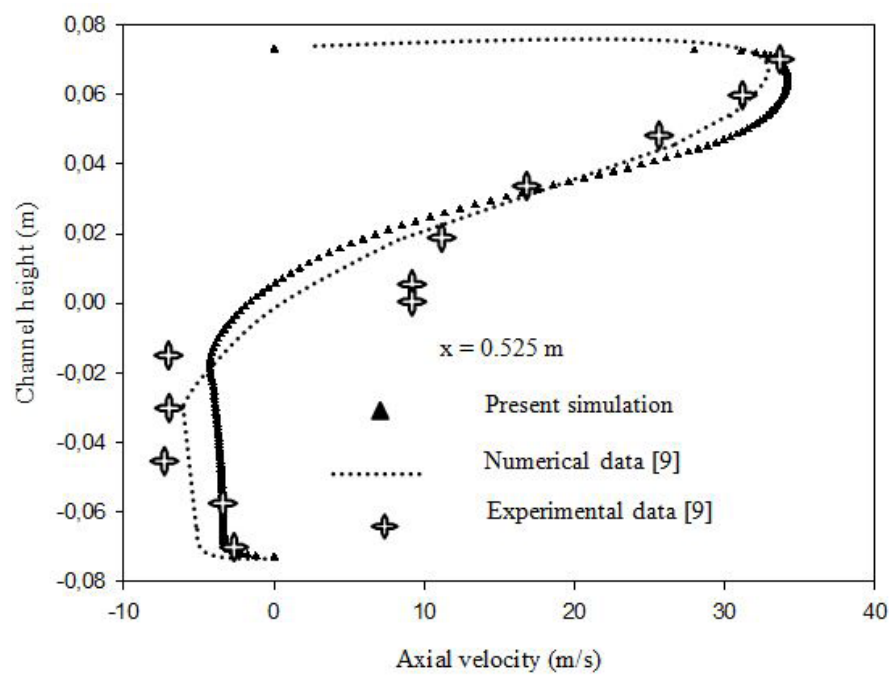

Fig. 3 Validation of the axial velocity profile with reported data [9].

\section{Results and Discussion}

The tow-dimensional structure of the near wall flow in the presence of upper and lower wall-mounted corrugated transverse baffles could be easily discerned by considering the stream-function field distribution plots in Fig. 4. The plots in Fig. 4 present the stream-function fields of turbulent channel flow through corrugated baffles using the standard $k-\varepsilon$ model for both the investigated cases (A and B). In case A, a staggered corrugated-upstream baffle pair is considered (see Fig. 1a) and in case B, a staggered corrugated-downstream baffle pair is considered (see Fig. 1b). Here the streamlines in the corrugated baffled channel are presented for different Reynolds number values $(R e=5,000,10,000,15,000$, and 20,000), as shown in Fig. 4 (a-d), respectively. The plots reveal the existence of three main regions. In the first region, just upstream of the corrugated baffle, the fluid is accelerated and arrives with an axial speed. At the approach of the corrugated baffles, the current lines are deflected. In the second region, located between the top of each corrugated baffle and the walls of the channel, the flow is accelerated due to the effect of cross-sectional reduction. In the third region, downstream of the corrugated baffles, the current lines are generated by the effect of flow expansion, thus leaving the section formed by the corrugated baffles and the walls. The most important phenomenon occurring in this zone is the formation of a recirculating flow whose extent is proportional to the Reynolds number.

Fig. 5 (a-d) presents the axial velocity profile plots for airflow in the channel with corrugated-upstream and corrugated-downstream baffles for four different transverse locations, $x=0.189$ $\mathrm{m}, 0.255 \mathrm{~m}, 0.345 \mathrm{~m}$, and $0.525 \mathrm{~m}$, measured downstream of the entrance, respectively. In the figure, the results of the corrugated-upstream baffles (case A) are compared with those of the corrugated-downstream baffles (case B). It is clearly noted that the fluid velocity values are almost negligible near the two obstacles, particularly in the downstream areas; this is caused by the presence of the recirculation zones. Far from these regions, the current lines become parallel, which leads to the progressive development of the flow. It is also worth noticing that the axial velocity increases in the region extending from the end of each corrugated baffle to the wall of the channel. This rise in velocity is caused by the presence of the corrugated baffles and also by the presence of recycling; hence, an abrupt change in the direction of the flow comes out. One can also notice that the largest velocity values are found near the top of the channel. The flow starts accelerating just after the second baffle, to finally reach values of the order of 4-20 times of the intake velocity, depending on the baffle model and Re values.

It is clear that changing the corrugated baffle model has a more reasonable impact on the upper side of the first corrugated baffle and on the upper left side of the second one; this is due to the deviation of the flow direction. The use of corrugated-downstream baffle shows better axial velocity distribution values over the corrugated-upstream baffle at all locations by increasing the size of the recirculation zone.

An axial representation of numerical results of velocity profiles as a function of Reynolds number is also presented in Fig. 5 to examine the two models of corrugated baffles. The Reynolds number is ranged from 5,000 to 20,000. The axial velocity for air flowing in the corrugated baffled channel with larger flow rate is found to be higher than that with smaller flow rate. The axial velocity augments with the augmentation of Reynolds number and thus, the $R e=20,000$ provides maximum speed.

In addition, the graphs indicate that the flow rate impacts significantly the recirculation magnitude behind the insulated baffle. As expected, the graphs show that the recirculation length augments with the flow Reynolds number. Consequently, the recirculation zones with longer streamwise extent and higher vorticity have higher contribution to the mixing and hence to the heat transfer, as reported and confirmed by Nasiruddin and Kamran Siddiqui [10].

The impact of the Reynolds number on the profiles of the thermal enhancement factor (TEF) along the upper wall for both the model cases of corrugated obstacles is shown in Fig. 6 (a-e). Changes for Reynolds numbers ranging from 12,000 to 32,000, we noted that the increase in Reynolds number changes the thermal performance significantly. These results are obtained because the increase in the Reynolds number increases the flow rate of introducing large areas of recycling, which leads to an acceleration of the air flow and also the intensity of the turbulence and consequently the heat transfer. The comparison of the plots in this same diagram indicates that the reconfiguration of the baffled channel has an impact on the thermal enhancement. The result analysis reveals that the channel case with two 


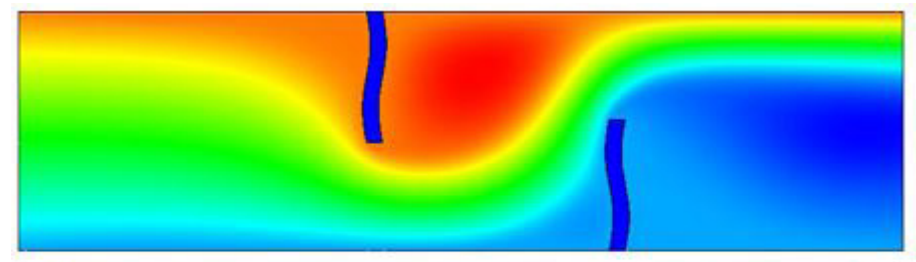

$\begin{array}{lllllllllll}0.01 & 0.02 & 0.03 & 0.04 & 0.05 & 0.06 & 0.07 & 0.08 & 0.09 & 0.1 & 0.11\end{array}$

(a)
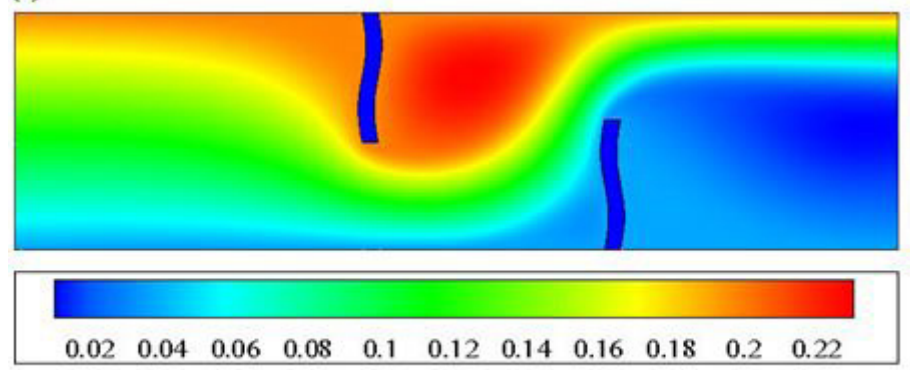

(b)
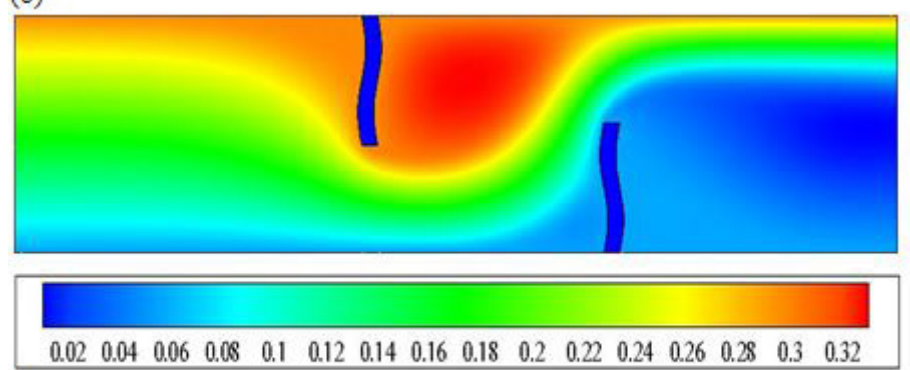

(c)
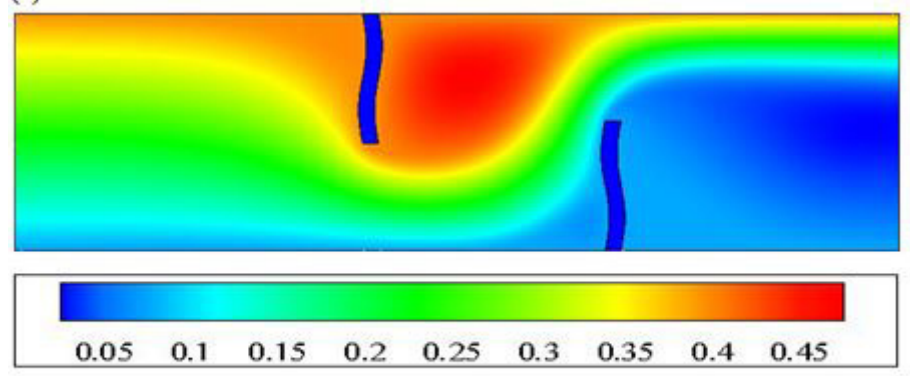

(d)

Case A
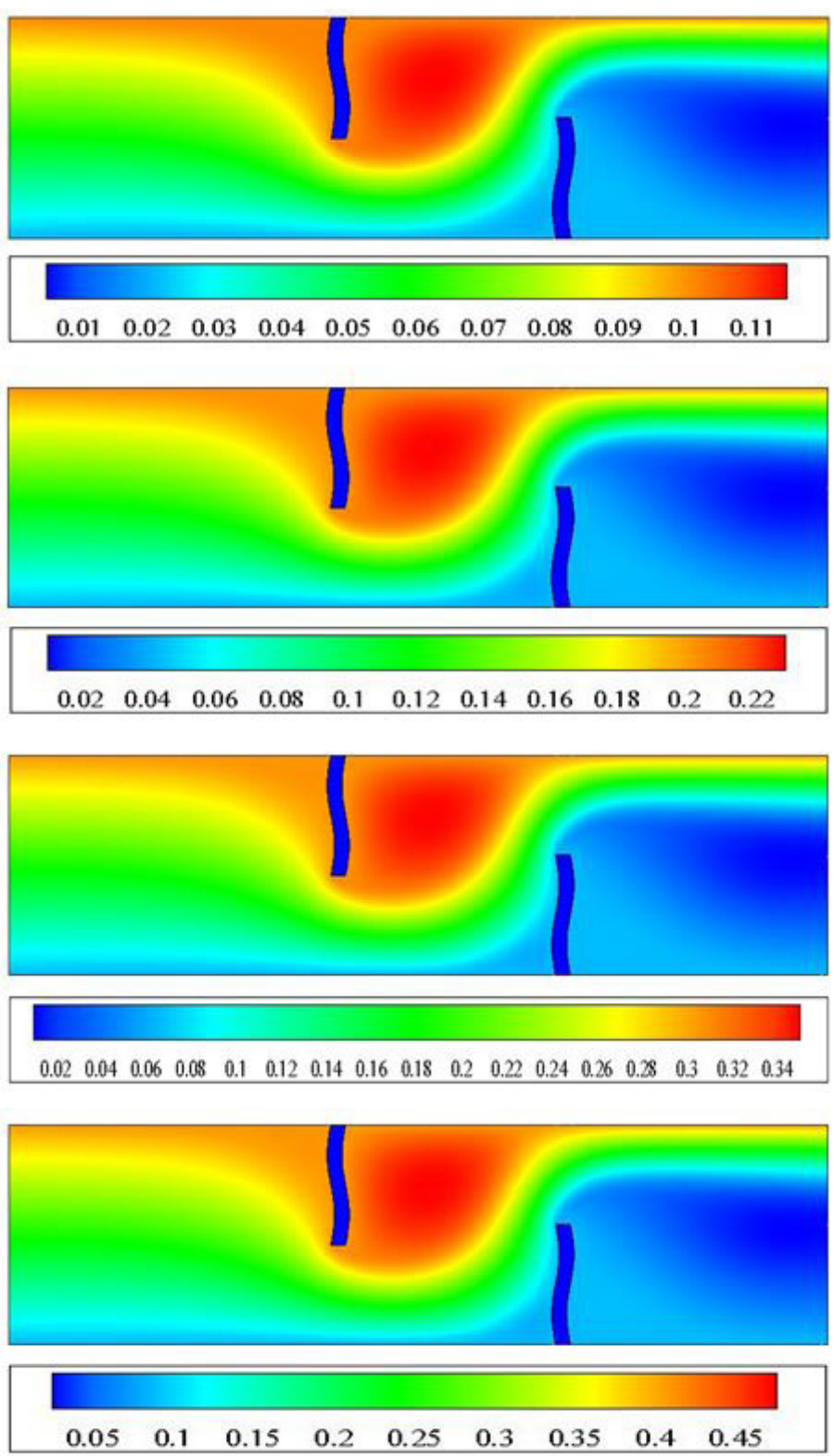

Case B

Fig. 4 Variation plots of stream-function fields with Reynolds number for both the corrugated baffle cases (case A with corrugated-upstream baffles, and case $B$ with corrugated-downstream baffles) and: a) $R e=5,000, b) \operatorname{Re}=10,000, c) \operatorname{Re}=15.000, d) R e=20,000$. Flow is from left to right.

Stream function values in $\mathrm{Kg} / \mathrm{s}$

corrugated-downstream baffles provides higher $T E F$ values of about 22 - $19 \%$ than the one with two corrugated-upstream baffles, at a given Reynolds number.

\section{Conclusion}

A detailed analysis of fluid flow and heat transfer through two wall-mounted corrugated solid-type baffles was carried out. The Finite Volume Method (FVM), by means of FLUENT was used to simulate the computational domain. QUICKscheme was used to solve the convection term, while SIMPLEalgorithm was adopted for velocity-pressure coupling. The effects of corrugated shape geometries (corrugated-upstream and corrugated-downstream) as well as Reynolds numbers were examined. In general, the corrugated-downstream baffles are thermal aeraulically better to the corrugated-upstream baffles at the same flow and temperature conditions. The thermal enhancement performance of corrugated-upstream baffles is upper than that of corrugated-downstream baffles, which indicates that the corrugated-downstream baffle is more advantageous than the corrugated-upstream baffle.

Further studies are recommended to determine the best position of the corrugated baffle on the channel walls. The best geometry parameters of the channel, such as the width, thickness, inclination, orientation (corrugated-upstream and corrugated-downstream), etc, must be determined. 


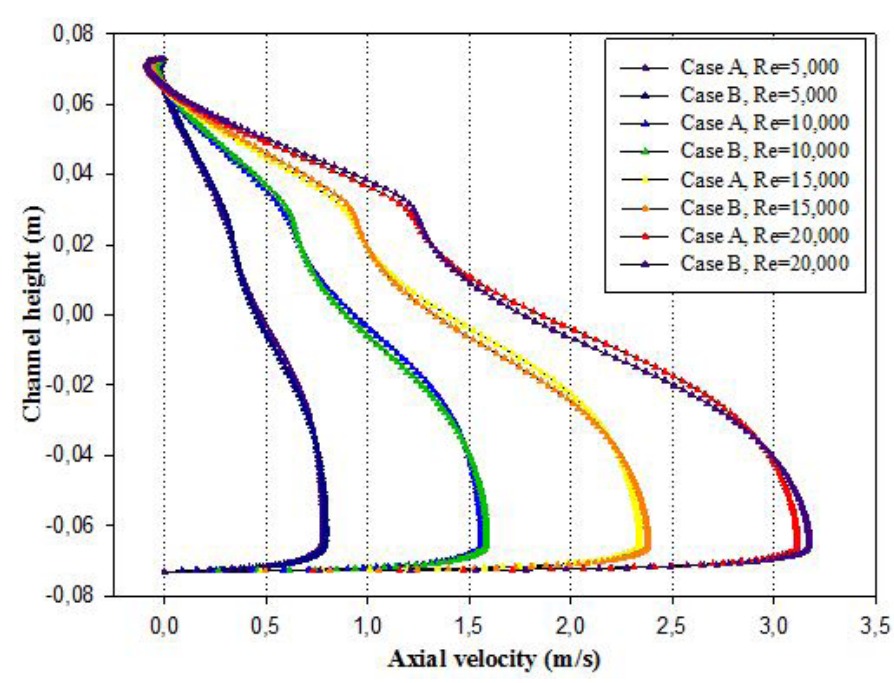

(a)

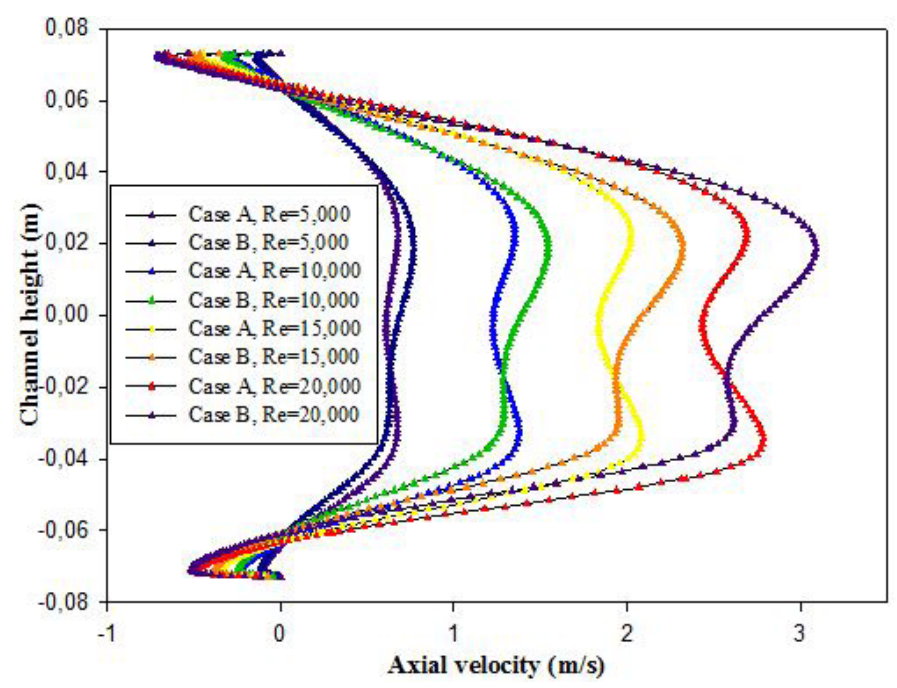

(c)

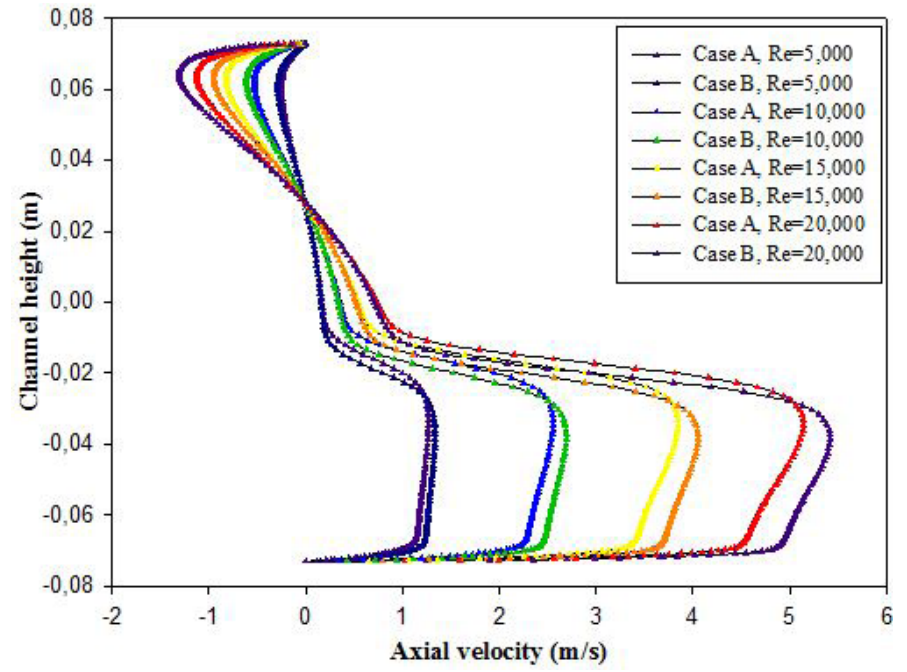

(b)

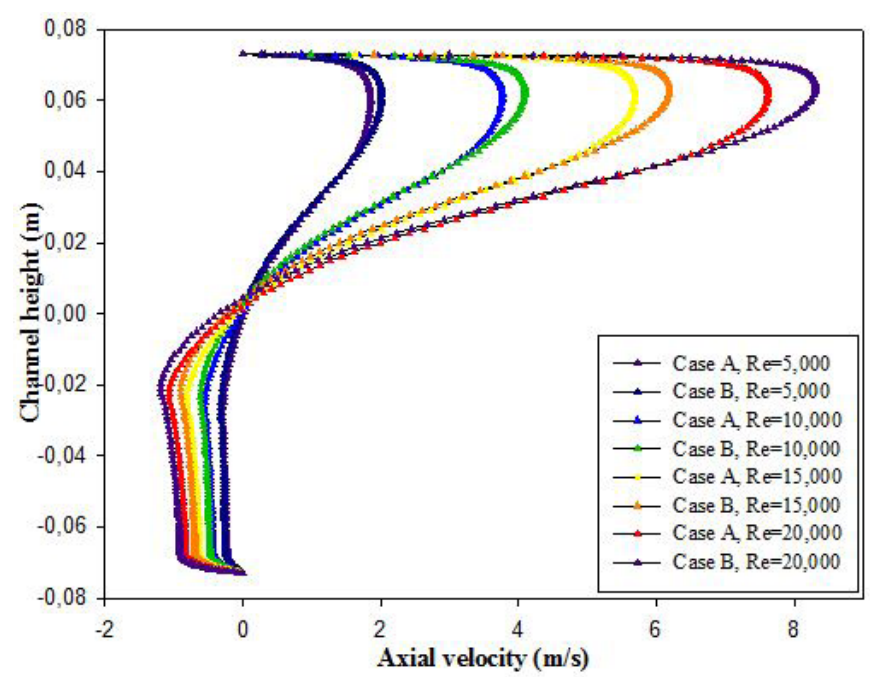

(d)

Fig. 5 Variation of axial velocity profiles with Reynolds number for both the baffle cases (case A: corrugated-upstream baffles, and case B: corrugateddownstream baffles) at different axial stations: a) $x=0.189 \mathrm{~m}, \mathrm{~b}) x=0.255 \mathrm{~m}$, c) $x=0.345 \mathrm{~m}$, d) $x=0.525 \mathrm{~m}$, measured downstream of the entrance.

$\begin{array}{cl}\text { Nomenclature } \\ C f & \text { Skin friction coefficient } \\ C_{1 \varepsilon} & \text { Constant used in the standard } k-\varepsilon \text { model } \\ C_{2 \varepsilon} & \text { Constant used in the standard } k-\varepsilon \text { model } \\ C_{\mu} & \text { Constant used in the standard } k-\varepsilon \text { model } \\ { }_{D} \mathrm{~h} & \text { Aeraulic diameter of the channel, } \mathrm{m} \\ f & \text { Friction factor } \\ G & \text { Production rate of the kinetic energy }\left(\mathrm{m}^{2} / \mathrm{s}^{2}\right) \\ H & \text { Height of air tunnel in channel }(\mathrm{m}) \\ h & \text { Corrugated-baffle height (m) } \\ h_{x} & \text { Convective heat transfer coefficient }\left(\mathrm{W} / \mathrm{m}^{2} \mathrm{~K}\right) \\ k & \left.\text { Turbulent kinetic energy (m } 2 / \mathrm{s}^{2}\right) \\ L & \text { Channel length (m) } \\ L_{1} & \text { Distance upstream of the first baffle }(\mathrm{m}) \\ L_{2} & \text { Distance downstream of the second baffle }(\mathrm{m}) \\ P & \text { Fluid pressure (Pa) } \\ P_{a t m} & \text { Atmospheric pressure (Pa) } \\ P i & \text { Corrugated-baffle distance (m) }\end{array}$

$\begin{array}{ll}P r & \text { Prandtl number } \\ R e & \text { Reynolds number } \\ U_{i n} & \text { Inlet velocity }(\mathrm{m} / \mathrm{s}) \\ \bar{U} & \text { Channel average velocity }(\mathrm{m} / \mathrm{s}) \\ u & \text { Fluid velocity in the } x \text {-direction }(\mathrm{m} / \mathrm{s}) \\ v & \text { Fluid velocity in the } y \text {-direction }(\mathrm{m} / \mathrm{s}) \\ w & \text { Thickness of corrugated-baffles }(\mathrm{m}) \\ x, y & \text { Cartesian coordinates }(\mathrm{m})\end{array}$

\section{Greek symbols}

$\varepsilon \quad$ Turbulent dissipation rate $\left(\mathrm{m}^{2} / \mathrm{s}^{3}\right)$

$\Gamma_{\phi} \quad$ Coefficient of turbulent diffusion

$\mu \quad$ Dynamic viscosity $(\mathrm{Kg} / \mathrm{m} \mathrm{s})$

$\mu_{e} \quad$ Effective viscosity $(\mathrm{Kg} / \mathrm{m} \mathrm{s})$

$\mu_{l} \quad$ Laminar viscosity $(\mathrm{Kg} / \mathrm{m} \mathrm{s})$

$\mu_{t} \quad$ Eddy viscosity $(\mathrm{Kg} / \mathrm{m} \mathrm{s})$

$v \quad$ Kinematics viscosity $(\mathrm{Kg} / \mathrm{m} \mathrm{s})$

$\rho \quad$ Fluid density $\left(\mathrm{kg} / \mathrm{m}^{3}\right)$ 


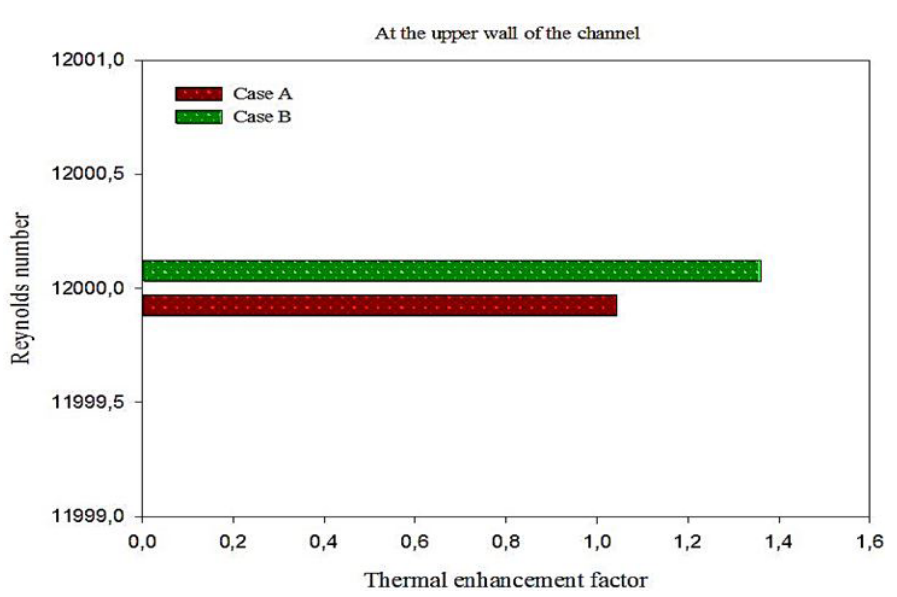

(a)

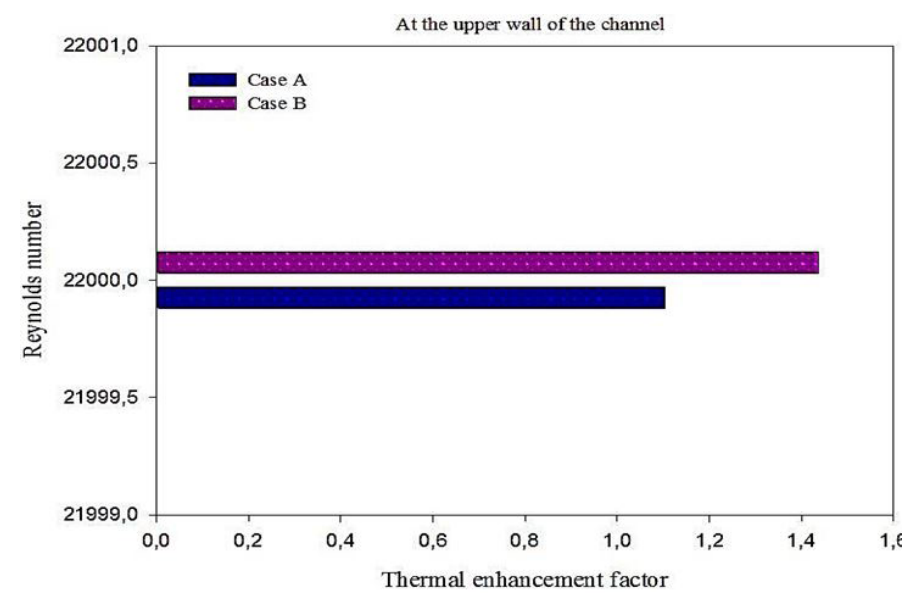

(c)

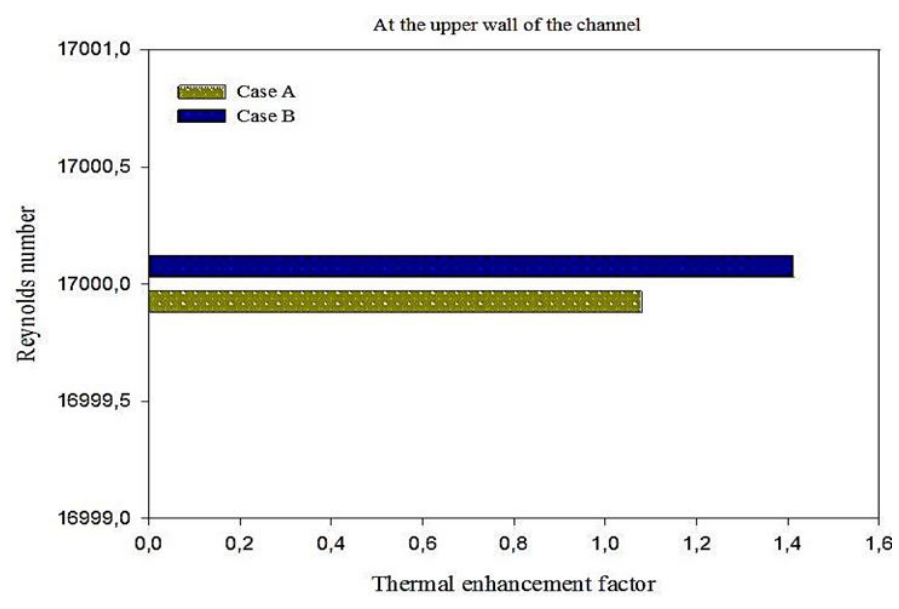

(b)

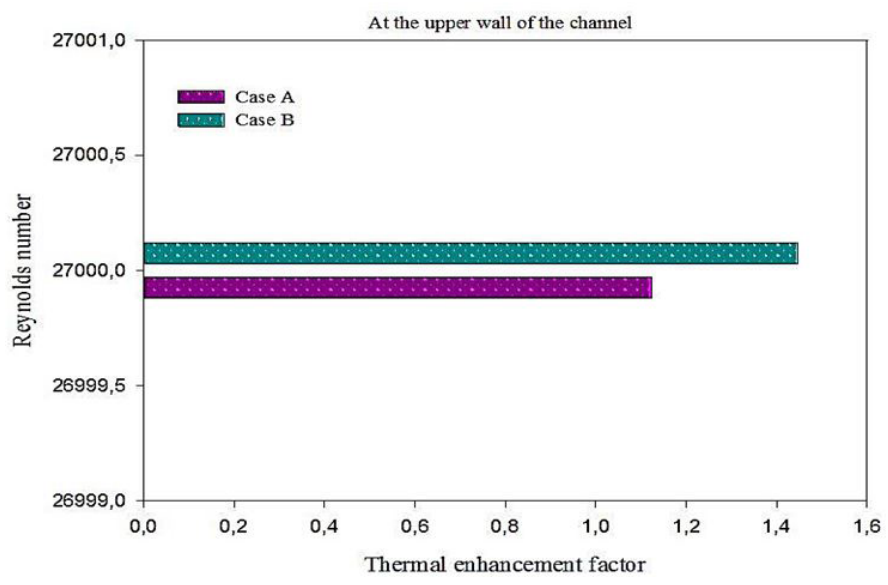

(d)

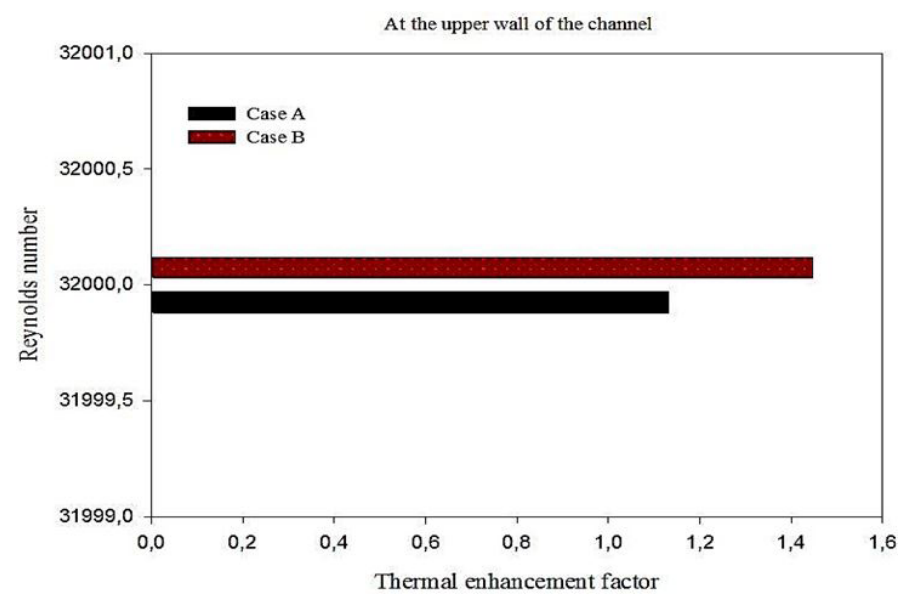

(d)

Fig. 6 Variation of thermal enhancement factor with Reynolds number for both the baffle cases (case A: corrugated-upstream baffles, and case B: corrugateddownstream baffles) at a) $R e=12,000$, b) $R e=17,000$, c) $R e=22,000$, d) $R e=27,000$, and (e) $R e=32,000$.

$\sigma_{k} \quad$ Constant used in the standard $k-\varepsilon$ model

$\sigma_{\varepsilon} \quad$ Constant used in the standard $k-\varepsilon$ model

$\tau_{w} \quad$ Wall shear stress $(\mathrm{Pa})$

$\phi \quad$ Stands for the dependent variables $u, v, T, k, \varepsilon$

$\triangle P \quad$ Pressure drop $(\mathrm{Pa})$

\section{Subscript}

Atmospheric
Effective

Fluid

Inlet of the computational domain

Laminar

Solid

Turbulent

Wall 


\section{References}

[1] Mokhtari, M., Gerdroodbary, M. B., Yeganeh, R., Fallah, K. "Numerical study of mixed convection heat transfer of various fin arrangements in a horizontal channel." Engineering Science and Technology. 20, pp. 11061114. 2017.

https://doi.org/10.1016/j.jestch.2016.12.007

[2] Promvonge, P., Sripattanapipat, S., Kwankaomeng, S. "Laminar periodic flow and heat transfer in square channel with $45^{\circ}$ inline baffles on two opposite walls." International Journal of Thermal Sciences. 49, pp. 963 975. 2010. https://doi.org/10.1016/j.ijthermalsci.2010.01.005

[3] Yongsiri, K., Eiamsa-ard, P., Wongcharee, K., Eiamsa-ard, S. "Augmented heat transfer in a turbulent channel flow with inclined detached-ribs." Case Studies in Thermal Engineering. 3, pp. 1-10. 2014. https://doi.org/10.1016/j.csite.2013.12.003

[4] Mellal, M., Benzeguir, R., Sahel, D., Ameur, H. "Hydro-thermal shellside performance evaluation of a shell and tube heat exchanger under different baffle arrangement and orientation." International Journal of Thermal Sciences. 121, pp. 138-149. 2017. https://doi.org/10.1016/j.ijthermalsci.2017.07.011

[5] Ligrani, P. "Heat transfer augmentation technologies for internal cooling of turbine components of gas turbine engines." International Journal of Rotating Machinery. 2013, ID 275653. 2013. https://doi.org/10.1155/2013/275653

[6] Kumar, A., Kim, M. H. "CFD analysis on the thermal hydraulic performance of an SAH duct with multi V-shape roughened ribs." Energies. 9, 415. 2016. https://doi.org/10.3390/en9060415

[7] Kumar, A., Kim, M. H. "Thermal hydraulic performance in a solar air heater channel with multi V-type perforated baffles." Energies. 9, 564. 2016.

https://doi.org/10.3390/en9070564

[8] Kumar, R., Kumar, A., Chauhan, R., Maithani, R. "Comparative study of effect of various blockage arrangements on thermal hydraulic performance in a roughened air passage." Renewable and Sustainable Energy Reviews. 81, pp. 447-463. 2018.

https://doi.org/10.1016/j.rser.2017.08.023

[9] Demartini, L. C., Vielmo, H. A., Möller, S. V. "Numeric and experimental analysis of the turbulent flow through a channel with baffle plates." Journal of the Brazilian Society of Mechanical Sciences and Engineering. 26(2), pp. 153-159. 2004. https://doi.org/10.1590/S1678-58782004000200006

[10] Nasiruddin, Kamran Siddiqui, M. H. "Heat transfer augmentation in a heat exchanger tube using a baffle." International Journal of Heat and Fluid Flow. 28(2), pp. 318-328. 2007. https://doi.org/10.1016/j.ijheatfluidflow.2006.03.020

[11] Menni, Y., Azzi, A. "Numerical analysis of thermal and aerodynamic fields in a channel with cascaded baffles." Periodica Polytechnica Mechanical Engineering. 62(1), pp. 16-25. 2018. https://doi.org/10.3311/PPme.10613

[12] Amraoui, M. A., Aliane, K. "Three-dimensional analysis of air flow in a flat plate solar collector." Periodica Polytechnica Mechanical Engineering. 62(2), pp. 126-135. 2018. https://doi.org/10.3311/PPme.11255

[13] Fodor, A. "Calculation of the temperature of boundary layer beside wall with time-dependent heat transfer coefficient." Periodica Polytechnica Mechanical Engineering. 54(1), pp. 15-20. 2010. https://doi.org/10.3311/pp.me.2010-1.03
[14] Rábai, G., Vad, J. "Aerodynamic study on straight, arc-swept and twisted stationary linear cascade blades." Periodica Polytechnica Mechanical Engineering. 53(1), pp. 33-40. 2009. https://doi.org/10.3311/pp.me.2009-1.05

[15] Hegedus, F., Rákos, R., Kullmann, L. "Experimental and numerical study on cavitating vortex shedding behind a square cylinder." Periodica Polytechnica Mechanical Engineering. 53(2), pp. 55-60. 2009. https://doi.org/10.3311/pp.me.2009-2.01

[16] Füle, P., Hernádi, Z. "Investigation of turbulent channel flow using local mesh refinement." Periodica Polytechnica Mechanical Engineering. 58(1), pp. 7-13. 2014 https://doi.org/10.3311/PPme.7182

[17] Goda, R., Bánhidi, L. "Investigation of average air velocity and turbulence intensity in a slot ventilated space." Periodica Polytechnica Mechanical Engineering. 58(2), pp. 77-81. 2014.

https://doi.org/10.3311/PPme.7264

[18] Bidar, B., Shahraki, F., Kalhori D. M. "3D Numerical modelling of convective heat transfer through two-sided vertical channel symmetrically filled with metal foams." Periodica Polytechnica Mechanical Engineering. 60(4), pp. 193-202. 2016. https://doi.org/10.3311/PPme.8511

[19] Khrabry, A., Smirnov, E., Zaytsev, D., Goryachev, V. "Numerical study of $2 \mathrm{~d}$ and $3 \mathrm{~d}$ separation phenomena in the dam-break flow interacting with a triangular obstacle." Periodica Polytechnica Mechanical Engineering. 60(3), pp. 159-166. 2016.

https://doi.org/10.3311/PPme.8948

[20] Fenyvesi, B., Horváth, C. "Investigation on the non-constant behavior of a vortex flow meter with narrow gauge pipe via conducting measurements and numerical simulations." Periodica Polytechnica Mechanical Engineering. 61(3), pp. 247-254, 2017. https://doi.org/10.3311/PPme.10816

[21] Launder, B. E., Spalding, D. B. "The numerical computation of turbulent flow." Computer Methods in Applied Mechanics and Engineering. 3(2), pp. 269-289. 1974. https://doi.org/10.1016/0045-7825(74)90029-2

[22] Dittus, F. W., Boelter, L. M. K. "Heat transfer in automobile radiators of tubular type." University of California Publications in Engineering. Vol. 2, Berkeley, California, University of California Press, 1930. https://doi.org/10.1016/0735-1933(85)90003-X

[23] Petukhov, B. "Heat Transfer and Friction in Turbulent Pipe Flow with Variable Physical Properties." Advances in Heat Transfer. 6, pp. $503-$ 564. 1970. https://doi.org/10.1016/S0065-2717(08)70153-9

[24] Patankar, S. V. "Numerical heat transfer and fluid flow." Hemisphere, New York, 1980.

[25] Leonard, B.P., Mokhtari, S. "Ultra-Sharp Nonoscillatory Convection Schemes for High-Speed Steady Multidimensional Flow." NASA TM 1-2568, NASA Lewis Research Center, 1990.

[26] Eiamsa-ard, S., Promvonge, P. "Numerical study on heat transfer of turbulent channel flow over periodic grooves." International Communications in Heat and Mass Transfer. 35, pp. 844-852, 2008. https://doi.org/10.1016/j.icheatmasstransfer.2008.03.008 